\title{
CORRIGENDUM
}

\section{Excision of HIV-1 DNA by gene editing: a proof-of-concept in vivo study}

R Kaminski, R Bella, C Yin, J Otte, P Ferrante, HE Gendelman, H Li, R Booze, J Gordon, W Hu and K Khalili

Gene Therapy (2016) 23, 696; doi:10.1038/gt.2016.45

Correction to: Gene Therapy (2016) 23, 690-695; doi: 10.1038/ gt.2016.41; published online 19 May 2016

The following statement should be noted under Conflict of Interest:

' $\mathrm{KK}, \mathrm{WH}$, and RK are named inventors on patents that cover the viral gene editing technology that is the subject of this published journal article. In addition to the foregoing interests, KK is a co-founder, board member, scientific advisor and holds equity in Excision Biotherapeutics, a biotech start-up which has licensed the viral gene editing technology from Temple University for commercial development and clinical trials. JG serves as an unpaid scientific advisor to Excision Biotherapeutics. The option to license the viral gene editing technology was signed before the acceptance of this manuscript. The authors declare that this work was produced solely by the authors and that no other individuals or entities influenced any aspects of the work including, but not limited to, the study conception and design; data acquisition, analysis and interpretation; and writing of the manuscript. The work was funded by the National Institutes of Health. No other entities provided funds for the work. The authors further declare that they have received no financial compensation from any other third parties for any aspects of the published work.' 